\title{
Development of a serum-free liquid medium for Bartonella species
}

\author{
Andreas Müller $^{1} \cdot$ Michael Reiter $^{1} \cdot$ Katrin Mantlik $^{1} \cdot$ Anna-Margarita Schötta $^{1}$ • \\ Hannes Stockinger ${ }^{1} \cdot$ Gerold Stanek $^{1}$
}

Received: 3 December 2015 / Accepted: 14 January 2016 /Published online: 2 February 2016

(C) The Author(s) 2016. This article is published with open access at Springerlink.com

\begin{abstract}
The genus Bartonella comprises numerous species with at least 13 species pathogenic for humans. They are fastidious, aerobic, Gram negative, and facultative intracellular bacteria which cause a variety of human and non-human diseases. This study focused on the development of a serum-free liquid medium for culture of Bartonella species. Some liquid media are available commercially but all of them use undefined supplements such as fetal calf serum or defibrinated sheep blood. Our intention was to create a reproducible liquid medium for Bartonella species that can simply be prepared. We tested several supplements that could potentially support the growth of Bartonella species. Slight growth improvement was achieved with glucose and sucrose. However, hemin in particular improved the growth rate. At a temperature of $37{ }^{\circ} \mathrm{C}$, a $\mathrm{CO}_{2}$ concentration of $5 \%$, a humidified atmosphere, and the use of the supplements glucose, sucrose, and hemin, we developed a medium that does not need serum as an undefined supplement any more. In conclusion, the newly developed medium supports growth of Bartonella species equal to the commercially available media but with the advantage that it has a serum-free formulation. It can be prepared fast and easy and is a useful tool in studying these bacteria.
\end{abstract}

Andreas Müller

Andreas.mueller@meduniwien.ac.at

Institute for Hygiene and Applied Immunology, Center for Pathophysiology Infectiology and Immunology, Medical University of Vienna, Kinderspitalgasse 15, 1090 Vienna, Austria

\section{Introduction}

Bartonella species are distributed worldwide (Angelakis et al. 2010; Bai et al. 2013), and some of these are regarded as emerging infectious agents. They are aerobic, Gram negative, facultative intracellular bacteria that cause a variety of human and non-human diseases. Bartonellae are pleomorphic, slightly curved rods belonging to the alpha-2 subgroup of Proteobacteria. Currently, 31 Bartonella species and three subspecies have been described, at least 13 of these being pathogenic for humans (Kaiser et al. 2011). Recognized forms of disease are cat-scratch disease, Carrion's disease, trench fever, bacillary angiomatosis, and endocarditis (Houpikian and Raoult 2003). The two most prominent Bartonella species in Europe are Bartonella henselae, the main causative agent of cat-scratch disease (Brenner et al. 1993; Welch et al. 1992), and Bartonella quintana, which causes trench or 5-day fever (Brenner et al. 1993; Munk and da Rocha-Lima 1917).

Bartonellae use a vast number of mammals as reservoirs and various arthropods such as fleas, lice, mites, and possibly also ticks as vectors (Jacomo et al. 2002; Rolain et al. 2003). Rodents form a large proportion of the identified reservoirs of Bartonella species. These bacteria occur in a wide variety of habitats, which results in difficult cultivation requirements. They are fastidious, slow-growing bacteria, and most of them require a humidified atmosphere with a temperature range of 30 to $37^{\circ} \mathrm{C}$ and a $\mathrm{CO}_{2}$ saturation of $5 \%$.

\section{Materials and methods}

\section{Bartonella strains}

Four strains were used in cultivation experiments: $B$. henselae Houston 1 ATCC 49882 and a $B$. henselae Houston 1 ATCC 
49882 modified BadA-negative strain obtained from the Biozentrum University of Basel (Dehio and Meyer 1997), RSE247; B. henselae Marseille, URLLY8 obtained from the Institute for Medical Microbiology and Infection Control (Riess et al. 2007); B. quintana NCTC 12899 and B. vinsonii NCTC 12905.

\section{Bacterial cultivation}

Bartonellae were grown either on Columbia blood agar (CBA) plates with $5 \%$ sheep blood (BioMerieux) or in an altered Schneider's liquid medium (aSM) (Riess et al. 2008). Colony-forming units (CFU) were counted using the dilution plate technique on CBA plates. Cultures were sampled every $24 \mathrm{~h}$ with three dilutions in triplicate. Cultures were checked daily using streak-plating, microscopy, and PCR. Colonies picked from CBA plates were stained with CFDA-SE cell tracer kit (Invitrogen) according to the manufacturer's instructions and observed via fluorescent microscopy (Labophot-2, Nikon) for morphology check. Strain specificity of the cultures was tested using an in-house PCR method with the primers fwAGATGATGATCCCAAGCCTTCTGG (Knap et al. 2007) and rev-AGTCCTCCCAGGCCCACCAATT, targeting the 16 to $23 \mathrm{~s}$ intergenic spacer region.

The LIVE/DEAD BacLight ${ }^{\mathrm{TM}}$ Bacterial Viability Kit (Invitrogen) for cell viability determination was used according to the manufacturer's instructions.

\section{Growth experiments}

During a co-culture study, we observed growth of $B$. henselae in an in-house Borrelia liquid medium and investigated this medium in further as a potential growth medium for Bartonella species. For all growth experiments, a basic medium (Table 1) was used which

Table 1 Composition of the basic medium

\begin{tabular}{ll}
\hline Inorganic salts & $(\mathrm{mg} / \mathrm{L})$ \\
\hline Calcium chloride anhydrous & 600 \\
Potassium chloride & 1600 \\
Potassium dihydrogen orthophosphate & 500 \\
Magnesium sulfate & 3000 \\
Sodium chloride & 2500 \\
Sodium bicarbonate & 500 \\
Disodium phosphate $\left(\mathrm{Na}_{2} \mathrm{HPO}_{4}\right)$ & 650 \\
Other components & \\
$\quad$ Malic acid & 50 \\
Succinic acid & 600 \\
$\alpha$-Ketoglutaric acid & 300 \\
Fetal calf serum & $10 \%(v / v)$ \\
\hline
\end{tabular}

derived from this Borrelia liquid medium. In order to improve the growth-promoting characteristics of the new medium, we tested several supplements which due to literature affect the growth of Bartonella species (Chenoweth et al. 2004; Riess et al. 2008; Sander et al. 2000). These tests included the carbohydrates mannose, galactose, glucose, fructose, and sucrose as sources of energy and other supplements such as hemin (Sigma-Aldrich). The combinations of the basic medium with the different supplements were tested by counting $\mathrm{CFU}$ and measuring the absorbance at $600 \mathrm{~nm}\left(\mathrm{~A}_{600}\right.$; Spectronic 200, Thermo Scientific and Lambda 25, Perkin Elmer).

\section{Functional analysis of $B$. henselae grown in the new medium}

The host cell invasion and intracellular replication are essential aspects of the Bartonella life and virulence cycles. Bartonella adhesin A (BadA) is a major virulence factor of B. henselae. Therefore, we analyzed the BadA expression of $B$. henselae Houston I and Marseille in the new liquid medium in comparison to CBA. Therefore, the $B$. henselae cultures were resuspended in SDS sample buffer and heated at $95{ }^{\circ} \mathrm{C}$ for $10 \mathrm{~min}$. The SDS-PAGE was performed in $12 \%$ gels. Coomassie Blue R250 (Applichem) was used to stain the gels.

For immunoblotting, proteins were blotted onto nitrocellulose membranes (Whatman) following by blocking in $5 \%$ skim milk powder in $25 \mathrm{mmol} / \mathrm{L}$ Tris- $\mathrm{HCl} \mathrm{pH} 8.0$, $2.7 \mathrm{mmol} / \mathrm{L} \mathrm{KCl}, 137 \mathrm{mmol} / \mathrm{L} \mathrm{NaCl}$, and $0.05 \%$ Tween 20 (Sigma-Aldrich). The incubation time was $8 \mathrm{~h}$ at $4{ }^{\circ} \mathrm{C}$. The membrane was incubated with a BadA-specific (Riess et al. 2004) or a monoclonal anti- $B$. henselae primary antibody (Abcam) for $1 \mathrm{~h}$, and for detection, a horseradish peroxidase-conjugated secondary antibody was used. Visualization was performed via chemiluminescence (Pierce).

\section{Statistical analyses}

The data were analyzed for each supplement tested using the Independent Samples $t$ test. At every data point, the error bars are shown representing the standard deviation. Statistical analyses were conducted using IBM SPSS Statistics software (version 22), with results considered significant if $P$ was $<0.01$.

\section{Results}

Compared to the basic medium, the growth of cultures was improved by the addition of glucose and sucrose (Fig. 1a, b), with the best results at 5 and $3 \mathrm{~g} / \mathrm{L}$ glucose. Glucose only showed a growth improvement to a concentration of $3 \mathrm{~g} / \mathrm{L}$. 
Fig. 1 Supplement-dependent growth of Bartonella. The basic medium with different glucose (a), sucrose (b), amine (c), or hemin (d) concentrations was inoculated with $B$. henselae Marseille $\left(1.0 \times 10^{5} \mathrm{CFU} / \mathrm{mL}\right)$. The bacterial growth was determined every $24 \mathrm{~h}$ in triplicate by measuring the $\mathrm{A}_{600} * 3 \mathrm{~g} / \mathrm{L}$ glucose (a), $5 \mathrm{~g} / \mathrm{L}$ sucrose (b), $10 \mathrm{mg} / \mathrm{L}$ amine (c), and $50 \mu \mathrm{mol} /$ L hemin (d) showed a significant difference from the control value without the respective supplement $(P<0.01)$

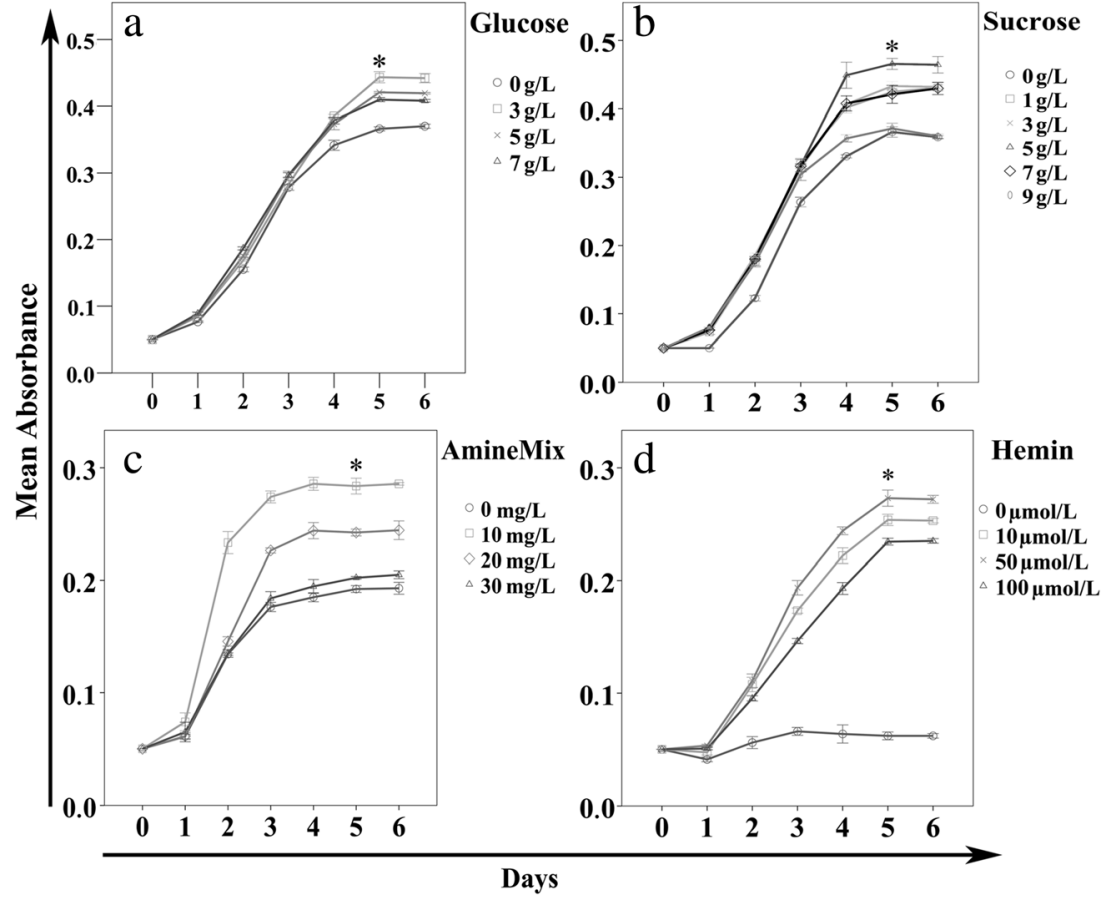

Higher concentrations resulted in a growth decline. The same effect was observed with sucrose as supplement. Up to a concentration of $5 \mathrm{~g} / \mathrm{L}$ sucrose had a growth improving effect. Higher concentrations resulted in a growth decline. In contrast, supplements of mannose and galactose resulted in less growth; fructose had no effect (data not shown). The N-ZAmine-A Mix (Sigma-Aldrich) as an amino acid source gave the greatest growth improvements at $10 \mathrm{mg} / \mathrm{L}$ (Fig. 1c). With hemin (Sigma-Aldrich), the best improvements were achieved with a concentration of $50 \mu \mathrm{mol} / \mathrm{L}$ (Fig. 1d). Hemin, a protoporphyrin IX containing a ferric iron ion, showed the best growth improving capacities of all supplements.

The medium composition giving the best growth for bartonellae is shown in Table 2. The corresponding growth curves for $B$. henselae Houston 1 ATCC 49882, modified $B$. henselae Houston 1 ATCC 49882, and modified $B$. henselae Marseille are shown in Fig. 2a. All three strains displayed good growth to a density of $1.0 \times 10^{8} \mathrm{CFU} / \mathrm{mL}$. Furthermore, we tested B. quintana and Bartonella vinsonii with the new medium showing even better growth results (Fig. 2b).

The Coomassie brilliant blue staining profiles of $B$. henselae Marseille cultivated on CBA or in the new medium formulation showed no prominent differences in the total protein composition (Fig. 3a). Immunoblotting with a $B$. henselae-specific monoclonal antibody showed no differences in the expression level of the 43-kDa epitope (Fig. 3b). BadA immunoblotting resulted in the typical ladder-like pattern (Riess et al. 2008) and gave no prominent differences in the BadA pattern between $B$. henselae Marseille cultivated on CBA and in the new liquid medium (Fig. 3c).

\section{Discussion}

We report the successful development of the first serum-free liquid medium for bartonellae. One of the most important components for a bacterial growth medium is a good carbohydrate source; however, initial tests with mannose, galactose, and fructose resulted in reduced growth or had no effect. In a genomic study, it was stated that $B$. henselae has the metabolic potential to catabolize glucose but lacks some important factors for glycolysis, such as the gene encoding

Table 2 Final medium composition

\begin{tabular}{ll}
\hline Inorganic salts & $(\mathrm{mg} / \mathrm{L})$ \\
\hline Calcium chloride anhydrous & 600 \\
Potassium chloride & 1600 \\
Potassium dihydrogen orthophosphate & 500 \\
Magnesium sulfate & 3000 \\
Sodium chloride & 2500 \\
Sodium bicarbonate & 500 \\
Disodium phosphate $\left(\mathrm{Na}_{2} \mathrm{HPO}_{4}\right)$ & 650 \\
Amino acids & \\
$\quad$ N-Z-Amine A Mix & 10,000 \\
Other components & \\
$\quad$ Malic acid & 50 \\
Succinic acid & 600 \\
$\alpha$-Ketoglutaric acid & 300 \\
Sucrose & 5000 \\
Glucose & 3000 \\
Hemin & $50 \mu \mathrm{mol} / \mathrm{L}$ \\
\hline
\end{tabular}


Fig. 2 Growth curves of Bartonella species in the developed medium. The final medium was inoculated with different Bartonella strain $\left(1.0 \times 10^{5} \mathrm{CFU} / \mathrm{mL}\right)$, B. henselae Marseille URLLY8, $B$. henselae Houston 1 ATCC 49882, a modified $B$. henselae Houston 1 ATCC 49882 RSE247 (a), Bartonella vinsonii and Bartonella quintana (b). The bacterial growth was determined every $24 \mathrm{~h}$ in triplicate by measuring the $\mathrm{A}_{600}$ and by quantifying the viable bacteria $(\mathrm{CFU} / \mathrm{mL})$. Note that all strains displayed good growth in the new developed medium

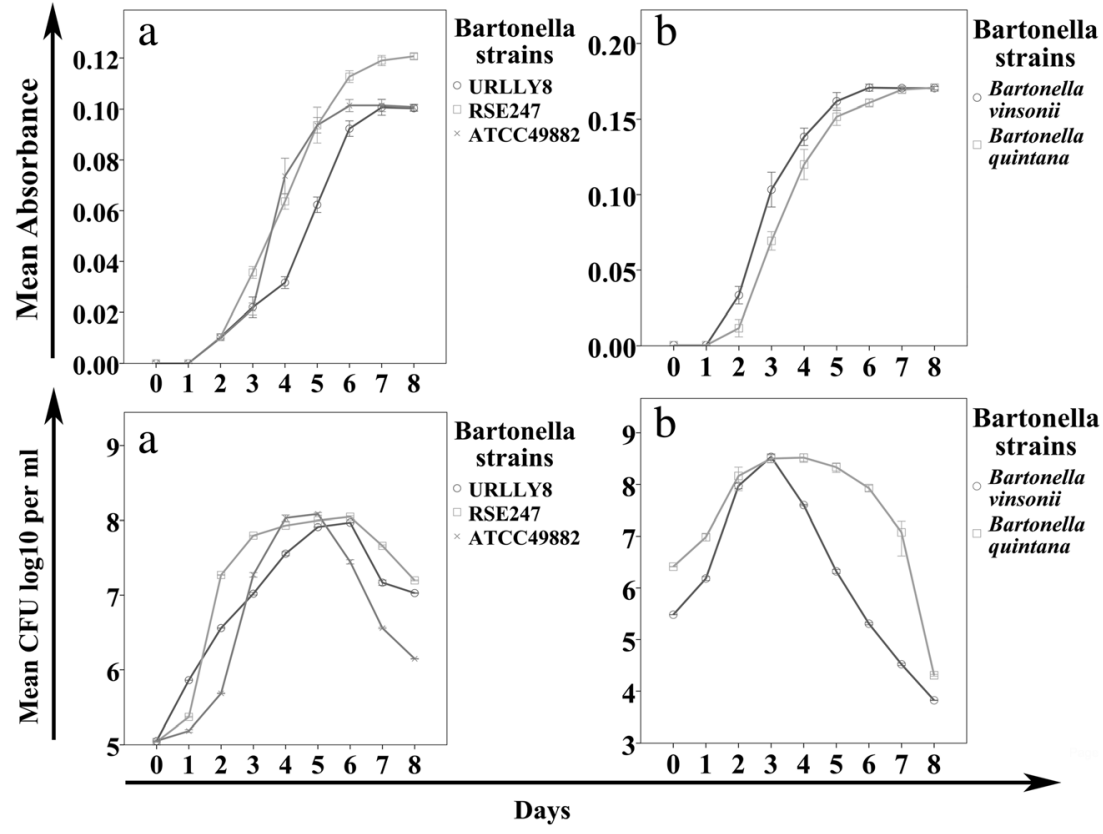

phosphofructokinase, and therefore, it was suggested that elements of the Entner-Doudoroff pathway bypass this otherwise critical step of glycolysis (Canback et al. 2002). This supports our finding that fructose had no effect on the bacterial growth and that glucose facilitated growth. The same result was found for mannose, galactose, and fructose in a study with modified Schneider's medium (Riess et al. 2008). The reason why mannose and galactose have a suppressive effect on the bacterial growth in this study is not yet understood.

The growth-improving effect of glucose is a controversial topic at present. Chenoweth et al. reported the opposite effect: $B$. henselae did not use glucose under the growth conditions they tested with an in-house medium (BBH-H) (Chenoweth et al. 2004). Thus, it is difficult to compare those results with our study where a different medium composition was used. In another study, a slight inhibition of growth was observed with $5 \%(w / v)$ glucose supplementation (Riess et al. 2008), a glucose concentration more than 10 times higher than in our trials. We observed the best growth improvement with the addition of $3 \mathrm{~g} / \mathrm{L}$ glucose (Fig. 1a), but increasing the glucose concentration to 5 or $7 \mathrm{~g} / \mathrm{L}$ resulted in a decrease of the
Fig. 3 Protein composition and immunoblotting of Bartonella henselae. Bartonella henselae was grown either on CBA plates as well as in the new liquid medium (NLM). Protein lysates of these cultures were visualized with Coomassie blue staining (a) and immunoblotting was carried out with a monoclonal antibody of the 43-kDa epitope of Bartonella henselae (b). For the immunoblot analysis of BadA, the same lysates were tested, and a BadA-negative Bartonella henselae strain ( $\mathrm{BadA}-$ ) was used as a negative control (c) a

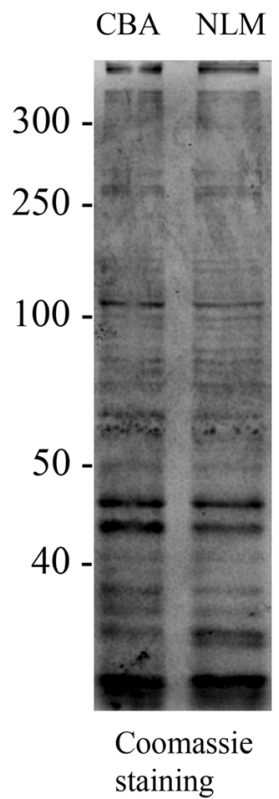

b

CBA NLM

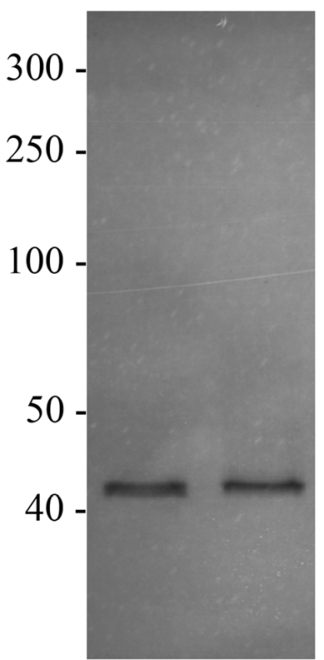

anti $43 \mathrm{kDa}$ epitope
C

BadA- CBA NLM

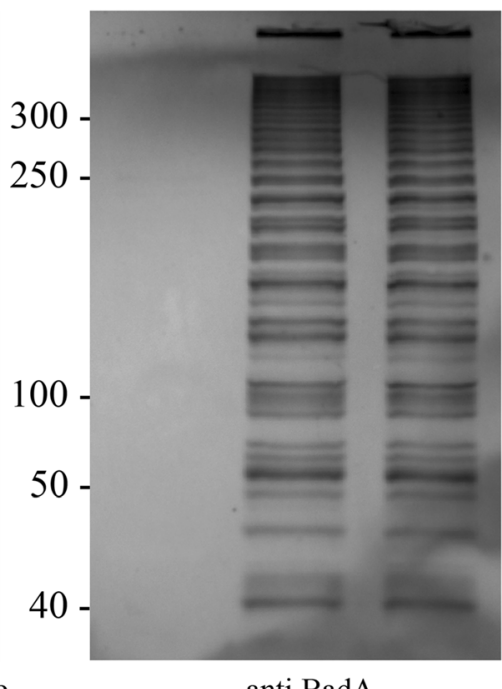

anti BadA 
growth rate, which could explain the slight inhibition observed with $50 \mathrm{~g} / \mathrm{L}$ (Riess et al. 2008).

The addition of sucrose was most effective at $5 \mathrm{~g} / \mathrm{L}$ (Fig. 1b). A similar effect was observed in another growth study, with the difference that the sucrose concentration was $50 \mathrm{~g} / \mathrm{L}$ (Riess et al. 2008).

For an amino acid source, we used the mixture N-ZAmine-A, which contains the most important amino acids and is easy to handle for medium preparation. A concentration of $10 \mathrm{mg} / \mathrm{L}$ showed the best growth improvements (Fig. 1c). The importance of amino acids for the growth of bartonellae has been shown (Chenoweth et al.) in a study measuring depletion of free amino acids from BBH-H medium by B. henselae (Chenoweth et al. 2004).

Iron is an essential nutrient for viability and pathogenicity in bacteria. In the eukaryotic host, bloodstream iron is sequestered by ferritin, lactoferrin, and transferrin (Gray-Owen and Schryvers 1996; Schaible and Kaufmann 2004); thus, bartonellae, as blood-borne pathogen, needs a system for scavenging iron. Several studies have investigated the ability of bartonellae to utilize hemin, an iron-containing porphyrin found in eukaryotic blood as hemoglobin (Carroll et al. 2000; Roden et al. 2012; Sander et al. 2000; Zimmermann et al. 2003). These studies showed that $B$. henselae possesses five and $B$. quintana possesses eight outer membrane proteins known as hemin-binding proteins, and findings indicated that hemin is essential for the growth, pathogenicity, and protection of the bacteria. In the present study, a concentration of $50 \mu \mathrm{M}$ hemin resulted in the best growth rate (Fig. 1d). A similar observation was made by Sander et al. (Sander et al. 2000).

The final medium composition including all growthfacilitating supplements (Table 2) was tested with the four Bartonella species used in this study (Fig. 2a, b). The growth yield for these species was between 1 and $5 \times 10^{8} \mathrm{CFU} / \mathrm{mL}$ with a corresponding $\mathrm{A}_{600}$ between 0.1 and 0.17 . In comparison with currently used liquid media for bartonellae, the maximum cell concentration was reduced by $0.5 \mathrm{log}$, but this did not affect the culture reaching the stationary phase. As in other studies, the cultures reached their stationary-phase after 6 to 7 days (Lynch et al. 2011; Riess et al. 2008).

The immunoblotting analysis of $B$. henselae Marseille grown in the new liquid medium showed the typical ladderlike band-pattern of BadA, a major pathogenicity factor of this Bartonella species. No differences were observed between the cultivation of $B$. henselae Marseille on CBA or in the new liquid medium (Fig. 3c). The protein composition did not show any prominent differences, and the immunoblotting with a $B$. henselae-specific monoclonal antibody revealed the same expression levels of the 43-kDa epitope of $B$. henselae (Fig. 3a, b).

To our knowledge, this is the first study that has developed a serum-free liquid medium for Bartonella. This reproducible medium can be prepared fast and easy and supports the growth of several Bartonella species. No changes of the protein expression pattern, including BadA, for $B$. henselae could have been observed. Therefore, the new liquid medium appears to be a useful tool in studying these bacteria of which some belong to the agents of emerging infectious diseases, distributed worldwide.

Acknowledgments We thank Christoph Dehio (Biozentrum, University of Basel) for providing us with the modified Bartonella henselae Houston 1 strain and the group of Volkhard A. J. Kempf (Institute for Medical Microbiology and Infection Control) for providing the Bartonella henselae Marseille strain.

Open Access This article is distributed under the terms of the Creative Commons Attribution 4.0 International License (http:// creativecommons.org/licenses/by/4.0/), which permits unrestricted use, distribution, and reproduction in any medium, provided you give appropriate credit to the original author(s) and the source, provide a link to the Creative Commons license, and indicate if changes were made.

\section{References}

Angelakis E, Billeter SA, Breitschwerdt EB, Chomel BB, Raoult D (2010) Potential for tick-borne bartonelloses. Emerg Infect Dis 16: 385-391

Bai Y, Malania L, Alvarez Castillo D, Moran D, Boonmar S, Chanlun A, Suksawat F, Maruyama S et al (2013) Global distribution of Bartonella infections in domestic bovine and characterization of Bartonella bovis strains using multi-locus sequence typing. PLoS One 8, e80894

Brenner DJ, O'Connor SP, Winkler HH, Steigerwalt AG (1993) Proposals to unify the genera Bartonella and Rochalimaea, with descriptions of Bartonella quintana comb. nov., Bartonella vinsonii comb. nov., Bartonella henselae comb. nov., and Bartonella elizabethae comb. nov., and to remove the family Bartonellaceae from the order Rickettsiales. Int J Syst Bacteriol 43:777-786

Canback B, Andersson SG, Kurland CG (2002) The global phylogeny of glycolytic enzymes. Proc Natl Acad Sci U S A 99:6097-6102

Carroll JA, Coleman SA, Smitherman LS, Minnick MF (2000) Heminbinding surface protein from Bartonella quintana. Infect Immun 68: 6750-6757

Chenoweth MR, Somerville GA, Krause DC, O'Reilly KL, Gherardini FC (2004) Growth characteristics of Bartonella henselae in a novel liquid medium: primary isolation, growth-phase-dependent phage induction, and metabolic studies. Appl Environ Microbiol 70:656663

Dehio C, Meyer M (1997) Maintenance of broad-host-range incompatibility group $\mathrm{P}$ and group $\mathrm{Q}$ plasmids and transposition of Tn5 in Bartonella henselae following conjugal plasmid transfer from Escherichia coli. J Bacteriol 179:538-540

Gray-Owen SD, Schryvers AB (1996) Bacterial transferrin and lactoferrin receptors. Trends Microbiol 4:185-191

Houpikian P, Raoult D (2003) Diagnostic methods. Current best practices and guidelines for identification of difficult-to-culture pathogens in infective endocarditis. Cardiol Clin 21:207-217

Jacomo V, Kelly PJ, Raoult D (2002) Natural history of Bartonella infections (an exception to Koch's postulate). Clin Diagn Lab Immunol 9: $8-18$ 
Kaiser PO, Riess T, O’Rourke F, Linke D, Kempf VA (2011) Bartonella spp.: throwing light on uncommon human infections. Int J Med Microbiol 301:7-15

Knap N, Duh D, Birtles R, Trilar T, Petrovec M, Avsic-Zupanc T (2007) Molecular detection of Bartonella species infecting rodents in Slovenia. FEMS Immunol Med Microbiol 50:45-50

Lynch T, Iverson J, Kosoy M (2011) Combining culture techniques for Bartonella: the best of both worlds. J Clin Microbiol 49:1363-1368

Munk F, da Rocha-Lima H (1917) Klinik und Ätiologie des sogen. "Wolhynischen Fiebers". (Werner-His'sche Krankheit) I. Klinischer Teil. Münch Med Wochenschrift 64:1357-1361

Riess T, Andersson SG, Lupas A, Schaller M, Schafer A, Kyme P, Martin J, Walzlein JH et al (2004) Bartonella adhesin a mediates a proangiogenic host cell response. J Exp Med 200:1267-1278

Riess T, Raddatz G, Linke D, Schafer A, Kempf VA (2007) Analysis of Bartonella adhesin A expression reveals differences between various B. henselae strains. Infect Immun 75:35-43

Riess T, Dietrich F, Schmidt KV, Kaiser PO, Schwarz H, Schafer A, Kempf VA (2008) Analysis of a novel insect cell culture mediumbased growth medium for Bartonella species. Appl Environ Microbiol 74:5224-5227
Roden JA, Wells DH, Chomel BB, Kasten RW, Koehler JE (2012) Hemin binding protein $\mathrm{C}$ is found in outer membrane vesicles and protects Bartonella henselae against toxic concentrations of hemin. Infect Immun 80:929-942

Rolain JM, Franc M, Davoust B, Raoult D (2003) Molecular detection of Bartonella quintana, B. koehlerae, B. henselae, B. clarridgeiae, Rickettsia felis, and Wolbachia pipientis in cat fleas, France. Emerg Infect Dis 9:338-342

Sander A, Kretzer S, Bredt W, Oberle K, Bereswill S (2000) Hemindependent growth and hemin binding of Bartonella henselae. FEMS Microbiol Lett 189:55-59

Schaible UE, Kaufmann SH (2004) Iron and microbial infection. Nat Rev Microbiol 2:946-953

Welch DF, Pickett DA, Slater LN, Steigerwalt AG, Brenner DJ (1992) Rochalimaea henselae sp. nov., a cause of septicemia, bacillary angiomatosis, and parenchymal bacillary peliosis. J Clin Microbiol $30: 275-280$

Zimmermann R, Kempf VA, Schiltz E, Oberle K, Sander A (2003) Hemin binding, functional expression, and complementation analysis of Pap 31 from Bartonella henselae. J Bacteriol 185: 1739-1744 